\title{
A estrutura e o mercado: uma análise comparativa do Plano Trienal e do PAEG
}

\author{
The structure and the market: Comparative analysis \\ of Plano Trienal and PAEG
}

LEANDRO VIZIN VILLARINO*

\begin{abstract}
RESUMO: Este artigo propõe uma análise dos textos Plano Trienal e PAEG, documentos de planeamento econômico brasileiro dos anos 1960, verificando, por um lado, os aspectos teóricos e conceituais sobre o seu diagnóstico retrospectivo, e, por outro, as condições socioeconômicas de cada projeto de texto prospectivamente como condição para a obtenção dos efeitos pretendidos. Essa análise não pretende apenas verificar a adequação de cada projeto à realidade brasileira, mas entender como os problemas internos de cada texto e suas relações podem ser elucidativos não apenas para a História das Ideias. mas para uma ampla reflexão sobre a história social, econômica e das instituições do Brasil.

PALAVRAS-CHAVE: história econômica; desenvolvimento econômico; planejamento econômico; História do Pensamento Econômico; golpe militar brasileiro.
\end{abstract}

ABSTRACT: This paper proposes an analysis of the texts Plano Trienal and PAEG, documents of economic planning in 1960s Brazil. We aim to check, on one hand, theoretical and conceptual aspects regarding its retrospective diagnosis, and, on the other, socioeconomic conditions each text projects for the future as condition for de achievement of their intended objectives. With such an analysis we do not aim to verify if the plans are suitable to the Brazilian reality, but to understand how internal problems of texts and its relations may be elucidatory no only to the History of Ideas, but also for a broad consideration of Economic, Social and Institutional History in Brazil.

KEYWORDS: economic history; economic development; economic planning; History of Economic Thought; Brazilian military coup.

JEL Classification: E61; H11; H12; N46.

* Doutor em História Econômica pela Faculdade de Filosofia, Letras e Ciências Humanas da Universidade de São Paulo - FFLCH/USP, E-mail: leandro.villarino@usp.br, Submetido: 19/Janeiro/2012; Aprovado: 16/Julho/2015. 


\section{INTRODUÇÃO}

Em geral, as análises históricas tendem a tomar como objetos privilegiados aqueles relacionados diretamente a fatos e dados, relegando para segundo plano as fontes discursivas que registram os princípios norteadores das decisões dos agentes. Tais fontes teriam pelo menos duas deficiências aos olhos do historiador: é sempre difícil distinguir o que tais discursos portam de análise objetiva e o que neles se submete a interesses particularistas ou "ideológicos"; além disso, formulações discursivas muito elaboradas, em geral, costumam ter pouca aplicabilidade prática, restringindo-se seus efeitos ao plano dos debates e das ideias. O presente trabalho defende que os discursos possuem um regime de objetividade próprio, que pode ser de grande relevância, não apenas para a história das ideias ou das mentalidades, mas também para a histórica social, econômica e das instituições. Tentaremos mostrar que as elaborações complexas em especial, tal como os planos econômicos que são nosso objeto de análise, são de grande valia, não para avaliar os dados reais ou interpretar a execução de políticas, mas para compreender as condições discursivas (aquilo que os pragmáticos americanos chamariam de background) mediante as quais essas práticas assumem papeis legítimos e efetivos. Para tanto, dividimos o ensaio em quatro partes além desta "Introdução": uma delimitação mais desenvolvida (embora demasiadamente sumária) do tema e da metodologia de análise; uma descrição mais precisa das fontes analisadas e da bibliografia de apoio; a análise propriamente dita; e uma conclusão que tenta recuperar os resultados da análise em uma perspectiva histórica mais ampla.

\section{DELIMITAÇÃO DO TEMA}

Se é verdade que o discurso constitui "normalmente a coisa mais fácil a ser pesquisada" (Knight, 1998, p. 226), então este trabalho deve começar desculpando-se por sua banalidade. De fato, a tarefa de interpretar um texto, identificando as motivações implícitas que o suscitam, parece encerrar o estatuto mais trivial para qualquer um que queira se dedicar a atividades intelectuais. Mas, para além de procedimentos que consistem sumariamente em remeter o conteúdo discursivo à instância exterior e determinante de um sujeito fundador há pelo menos outras duas formas (ou, ainda, uma forma dupla), por assim dizer, foucaultianas, de se considerar os discursos: uma arqueologia do saber retrospectiva, que busca reconstituir as condições históricas de legitimidade de um discurso, condições tais que Foucault chama de epistéme; e uma genealogia do poder prospectiva, que visa a identificar como práticas discursivas se integram a dispositivos não discursivos de execução de poder e controle. Não se trata de perguntar: "quais as intenções de seus autores?"; "que interesses ocultos porta este texto?"; e sim: "que fundamentos cognitivos permitem sua compreensão da realidade?"; "que pressupostos lhe permitem encadear causalidades?”; "que racionalidade é atribuída aos atores do pro- 
cesso?"; "que disposição de coisas, quais dispositivos de intervenção o discurso julga necessários à consumação de seus efeitos pretendidos?”.

É a partir dessa dupla referência que tentaremos analisar os dois programas de planejamento em questão, o Plano trienal de desenvolvimento econômico e social (1963-1965) (Presidência da República, 1962; doravante referido como Trienal) e o Programa de ação econômica do governo (Ministério do Planejamento e Coordenação Econômica, 1964; doravante PAEG). Ou seja, por um lado, tentar descobrir "seus princípios de orientação, as regras de formação de seus conceitos, seus elementos teóricos, e assim por diante" (Foucault, 2007, pp. 35-36) ${ }^{1}$ que denotem as continuidades e rupturas entre esses textos; por outro, identificar o modo como cada um se relaciona com a prática de governo, com os dispositivos (na verdade, mais com a carência de dispositivos) de controle governamental da economia brasileira. Vários aspectos nos permitem qualificar preliminarmente a relação entre esses dois programas como objeto privilegiado para tal análise.

Em primeiro lugar, apesar das diferenças entre as datas de publicação de cada plano ser inferior a dois anos (o Trienal é de dezembro de 1962, o PAEG, de novembro de 1964), o período que os separa marca uma ruptura no quadro institucional brasileiro que apresenta severas repercussões nas mais diversas esferas da sociedade. Com efeito, substitui-se uma democracia parlamentar efetiva embora "populista" por um governo militar autoritário e centralizador, sem compromisso com o debate público e com as liberdades de expressão intelectual, jornalística e cultural. A historiografia social costuma representar os anos pré-1964 como a culminância de um longo período de efervescência política e cultural, propiciado pelo contexto relativamente democrático e subitamente interrompido pela intervenção violenta, repressiva e arbitrária do Golpe. Vieira apresenta um dentre vários exemplos possíveis: para a autora a situação cultural pré-1964 é marcada por um "compartilhamento de ideias, projetos e atitudes [...] que foram sustados pela repressão, pela censura e pela imposição de um projeto conservador de desenvolvimento nacional" (Vieira, 2010, p. 158; colchetes nossos). Por sua vez, Wallerstein se refere ao Golpe a partir de seus determinantes econômicos: diante da falta do apoio político necessário a qualquer alternativa, à direita e à esquerda, de solução da crise econômica, o caminho das reformas, escolhido pelo governo esquerdista de Goulart, foi barrado pela direita com o "uso pontual [expeditious] da força", que teria assumido um "poder persistente por si mesmo" (Wallerstein, 1980, p. 34). Sendo assim, como os novos parâmetros institucionais se refletem na prática de planejamento? De que modo cada plano se relaciona com o panorama sociocultural que lhe serve de contexto? Tais planos não seriam pontos importantes para

\footnotetext{
${ }^{1}$ Não estaríamos sendo totalmente transparente se não indicássemos que nossa análise dos programas, especialmente do PAEG, é totalmente tributária das reflexões sobre "governamentalidade" e "liberalismo" em Foucault (2007; 2008); mas tal referência, a princípio, consiste mais em uma "inspiração" geral, pois seria demasiado imprudente recorrer a esses conceitos levantados para tratar de problemas europeus dos séculos XVIII e XIX sem considerar uma série de questões e mediações que em muito ultrapassariam os limites de um artigo.
} 
estudar a relação pouco explorada entre esse contexto sociocultural e as condições econômicas concomitantes?

Além disso, as equipes econômicas que elaboraram o Trienal e o PAEG são encabeçadas por Ministros do Planejamento que possuem visões sobre economia bem diferentes, se não opostas: o "desenvolvimentista" Celso Furtado, no primeiro, e o "ortodoxo" Roberto Campos, no segundo. Essa diferença em nível pessoal ou "ideológico" pode assumir uma perspectiva histórica de maior fôlego se lembrarmos como a historiografia tem qualificado o PAEG (e as reformas que dele decorreram) a partir de seu papel de reestruturação ou reorientação do Estado brasileiro e de sua relação com o setor privado. Os próprios formuladores mais ativos do PAEG tentam, retrospectivamente, apresentar seu programa como um avanço significativo das instituições e da racionalização macroeconômica do setor público no Brasil (Campos et al., 1976, caps. 4 e 6, especialmente pp. 60-63). Essa interpretação como ruptura, embora frequentemente reconsiderada sob perspectiva crítica, é corroborada por vários autores. Fishlow argumenta que o Golpe constituiu a primeira oportunidade para a tradição ortodoxa brasileira de levar a cabo um programa completo de intervenção e estabilização (Fishlow, 1974, p. 8). Macarini, com ironia, caracteriza a política econômica do Governo Castello Branco pela obsessão com "a inflação (a origem de todos os males)" e com a implementação de uma "nova racionalidade, alicerce firme do desenvolvimento" (Macarini, 2005, p. 55). Oliveira (1981) e Bercovici (2010), considerando, respectivamente, as reformas tributária e administrativa do setor público, insistem também no caráter reformador e "racionalizante" do programa. Já Zini Jr. e Hermann, tratando especificamente da reforma financeira, admitem a intenção de reorientação presente no PAEG, mas ressaltam que as transformações efetivas esbarraram em problemas de ordem estrutural e institucional da economia brasileira (Zini Jr., 1982, cap. 2, especialmente pp. 88-90; Hermann, 2002, pp. 75-82). Ianni reconhece a profundidade das reformas, mas as identifica com "boa parte do programa de reformas de base debatido nos anos 1962-1964", embora aplicado com "sentido" diferente (Ianni, 2009, p. 221). Em suma, a bibliografia parece indicar que a diferença "ideológica" que separa Campos de Furtado encerraria também efeitos práticos na forma de se pensar e organizar o Estado brasileiro, não obstante alguns autores sugerirem a incompletude da transformação ou continuidades pontuais com projetos anteriores. Qual seria, precisamente, aquela reorientação de "sentido" de que fala Ianni? Até que ponto essas diferenças de perspectiva se refletem na elaboração dos planos? Suas eventuais divergências são específicas e casuais ou obedecem a princípios de racionalização diferentes?

Se é relativamente consensual que o PAEG marca uma ruptura importante em relação às instituições estatais brasileiras pré-1964, do ponto de vista da execução de políticas de estabilização de curto prazo, a historiografia tende a identificar continuidades entre suas medidas e as do Trienal. Sochaczewski condiciona o PAEG a "um governo de força capaz de levar adiante a maioria das propostas do Plano Trienal” (Sochaczewski, 1983, p. 218). Resende, num texto clássico, considerando os planos primordialmente pela perspectiva das variáveis de política macroeconô- 
mica verificadas, defende que, na prática, os dois planos adotaram medidas bastante similares de estabilização "ortodoxa"; o poder repressivo propiciado pelo governo militar é que teria conferido ao PAEG a capacidade de aplicar uma política salarial restritiva, que seria o "porto-chave" do sucesso relativo (ou menor fracasso) do PAEG em relação ao Trienal no que concerne à estabilização (Resende, 1982, p. 802). Partindo-se dessa semelhança geral de práticas, cabe interrogar se tal continuidade reflete o conteúdo textual dos planos ou se dá à revelia de suas diferenças fundamentais. E quanto à ruptura explícita sobre a política salarial? Trata-se apenas de uma questão de força político-policial ou a diferença sustenta-se sobre um projeto distinto de desenvolvimento?

Prosseguiremos agora a uma melhor descrição das fontes e à análise propriamente dita dos planos. Na conclusão, tentaremos reconsiderar algumas das questões levantadas à luz dos resultados analisados, não com o objetivo de respondê-las definitivamente, mas de mostrar como a perspectiva adotada pode contribuir para uma reconsideração da interpretação histórica.

\section{FONTES}

As duas fontes básicas de análise são os textos divulgados do Trienal e do PAEG, respectivamente pela Presidência da República (PR, 1962) e pelo Ministério do Planejamento e Coordenação Econômica (MPCE, 1964). Além disso, tomaremos como fontes de apoio alguns textos de cunho biográfico (Furtado, 1985, 1989; Campos, 1994) ou histórico-analítico (Furtado, 2007; Campos e Simonsen, 1976; Simonsen, 1964) de autores diretamente relacionados à elaboração dos programas. Esse recurso, que qualificaremos como "bibliografia" por não receber uma análise sistemática como as fontes propriamente ditas, tem por objetivo menos depurar o que há de Furtado no Trienal ou de Campos no PAEG do que levantar algumas indicações contextuais mais específicas, os fatos e dados que os executores tinham diante de si e a experiência intelectual que lhes permitia compreender esses fatos e dados e projetar intervenções sobre eles.

\section{ANÁLISE}

Qual o conceito de planejamento subjacente ao Plano Trienal? Essa pergunta não pode ser respondida sem referência a determinada concepção geral de desenvolvimento econômico, bem como à especificidade que este teria adquirido no Brasil ou, conforme o jargão da época, em "países de economia subdesenvolvida". Embora o plano apresente recorrentemente o termo "planificação", esta nada tem que ver com o planejamento central minucioso da produção e da alocação de bens e recursos, do qual o Trienal (e também o PAEG) tenta sempre se distanciar: o texto recorre ao argumento liberal clássico segundo o qual o progresso do conhecimento econômico sobre as condições de crescimento e o comportamento dos 
agentes teria permitido "o desenvolvimento de técnicas da planificação adaptadas às economias de livre-empresa" (PR, 1962, p. 13). Ou seja, partindo-se de determinados padrões de comportamento dos empresários, seria possível imaginar um governo capaz de determinar os rumos da economia sem recorrer à centralização das decisões econômicas mais elementares: "identificados estes padrões, assim como os fatores principais que condicionam o comportamento do empresário-investidor, já não seria difícil conceber políticas visando a orientar o processo de formação de capital em economias de livre-empresa" (idem, p. 14). Em suma: não um planejamento que decide o rumo da economia, mas que apenas o orienta. Mas orienta para onde? E como?

É o sentido dessa orientação que revela a importância da perspectiva histórica de quem elabora o texto. Pois qual foi a marca da histórica econômica brasileira no período imediatamente anterior ao Trienal? Obviamente o processo de industrialização. Mas esse processo, segundo o plano, não pode ficar sem duas qualificações fundamentais: trata-se de uma industrialização acelerada, pois tardia, e voltada para substituir por equivalentes domésticos os produtos importados já consumidos no país. Portanto, em contraste com a dos países desenvolvidos, a industrialização no Brasil teria duas peculiaridades: uma maior velocidade de sua implementação e, consequentemente, uma maior velocidade na alteração das relações econômicas internas e com o exterior - enfim, "rápidas e profundas modificações estruturais" (idem). Essa repentina transformação da estrutura econômica, por sua vez, não se limita a guinadas pontuais, mas tende a estabelecer problemas duradouros e cumulativos: “essas modificações estruturais 'espontâneas' dão lugar a desequilíbrios em cadeia, com a deficiência de investimentos infraestruturais, formação de pontos de estrangulamento em setores básicos, utilização inadequada da capacidade para importar, formação de capacidade ociosa etc." (idem). Com isso - e aqui começa a se manifestar uma certa reversão quanto à possibilidade de políticas governamentais conjugáveis com o livre empreendimento -, ficam prejudicadas as expectativas e a capacidade de atuação do "empresário-investidor", pois "provocando descontinuidade nos processos, [as mudanças estruturais] alteram as tendências empiricamente comprovadas, reduzindo o valor da experiência passada, como base para a ação projetiva" (idem; colchetes nossos). É nesse vazio deixado pelo constrangimento das mudanças estruturais sobre o comportamento dos investidores privados que o planejamento do Estado encontra sua função: "antecipar as principais modificações estruturais requeridas para a manutenção de um determinado ritmo de desenvolvimento e indicar as medidas a serem tomadas a fim de que os investimentos, considerados essenciais àquelas modificações, sejam feitos oportunamente" (idem).

Em poucas palavras: o desenvolvimento dos "países subdesenvolvidos" teria uma peculiaridade distintiva em suas rápidas mudanças estruturais, que agiriam como fator disruptivo da capacidade de racionalização empírica e preditiva condicionante do investimento privado. Nesse contexto, o Estado teria a função indispensável de manter e orientar o investimento de recursos, de modo a impedir que a velocidade das mudanças e a ausência ou viés indesejável do fluxo de investimento 
provoquem desequilíbrios cumulativos. Como os agentes governamentais, cuja ação deveria se basear nos padrões comportamentais dos empresários, são capazes de superar a ruptura desses mesmos padrões, este é um problema com o qual o texto não lida... Mas trata-se de uma questão menor ${ }^{2}$; o que realmente interessa é como o Plano concebe uma realidade econômica "natural" ou "espontaneamente" (os autores não deixam de usar o termo, embora as aspas denotem certo constrangimento; ver p. 14) propensa a produzir desequilíbrios, dentro da qual a ação "artificial" ou "planejada" do Estado teria por objetivo orientar investimentos corretivos.

Esse diagnóstico dos desequilíbrios econômicos como decorrentes das mudanças estruturais, aliado à capacidade (ou necessidade) do Estado como agente corretivo dos desequilíbrios, perpassará praticamente todas as passagens de análise retrospectiva e de projeções do texto. A começar pela definição do "mais importante de todos os objetivos - a manutenção de uma elevada taxa de crescimento do Produto" (idem, p. 18). Em primeiro lugar, o termo manutenção indica que o Plano se atribui alguma continuidade em relação ao padrão de crescimento que marca a década de 1950: se os desequilíbrios têm origem na ausência (ou no equívoco) de orientação governamental dos investimentos, basta que estes sejam devidamente orientados para que a expansão econômica se sustente com estabilidade. O planejamento assume aqui a função de superar o dilema teórico ("ortodoxo") entre inflação e crescimento: "esse processo de substituição de importações, inseparável do desenvolvimento atual da economia brasileira, não se pode realizar sem pressão inflacionária a menos que a economia seja submetida a um planejamento capaz de antecipar aquelas modificações estruturais" (idem, p. 32; grifo nosso). Reciprocamente, será a capacidade planejadora do governo que permitirá conciliar um esforço para "reduzir a pressão inflacionária" com a aceleração do crescimento: "a utilização mais racional dos recursos, decorrente do planejamento, deverá substituir o efeito positivo que exerce a pressão do excedente de demanda monetária sobre o conjunto das atividades produtivas" (idem, pp. 44-45).

Nosso recorte do texto certamente exagera, fazendo o planejamento parecer quase uma panaceia; é difícil negar, porém, que o plano expressa um otimismo excessivo em relação à capacidade e aos efeitos da ação planejadora. Talvez isso encontre suas origens em uma certa "ilusão furtadiana" quanto à robustez e autonomia da economia brasileira. Lembremos como uma das passagens mais célebres da Formação econômica do Brasil é aquela que trata do "deslocamento do centro dinâmico" (Furtado, 2007, pp. 274 s.), segundo o qual, como consequência da

\footnotetext{
${ }^{2}$ As inconsistências, ambiguidades e hesitações que serão constantemente destacadas na análise do Trienal não têm o objetivo de desqualificar a argumentação do texto, o que, dada a perspectiva histórica de que dispomos e as condições de formulação do plano, seria uma pretensão pouco generosa. É por isso, aliás, que omitimos aquela que talvez seja a principal ambiguidade, tão menos interessante quanto mais problemática: que o plano oscile entre uma meta de crescimento de $7 \%$ e preocupações com o "grau de utilização da capacidade produtiva" (ver PR, 1962, p. 44-5). O interesse das "hesitações" no presente trabalho não é revelar inconsistências, mas sugerir como os fundamentos cognitivos implícitos no plano parecem ter chegado a um ponto em que são incapazes de resolver determinados impasses.
} 
crise de 1929, o elemento dinamizador da economia brasileira teria deixado de ser o setor exportador e se internalizado por um processo duplo: a descoberta de um instrumento governamental de manutenção da demanda efetiva, por meio da política de compra inflacionária do café, e o consequente interesse em reverter recursos para esse mercado interno, dado seu fortalecimento em relação à demanda externa. Esse processo levou à intensificação dos investimentos industriais de substituição de importações, de modo que "o fator dinâmico principal, nos anos que se seguem à crise, passa a ser, sem nenhuma dúvida, o mercado interno" (idem, p. 278).

Ora, essa perspectiva é fundamental para a caracterização do desenvolvimento imediatamente anterior ao plano, chamado de "fase superior da substituição de importações", na qual teriam se intensificado os investimentos em infraestrutura e indústrias de base, bem como a necessidade de recursos inflacionários que os financiassem. Evidentemente, esse salto final de autonomia só pode ser visto com otimismo mediante uma perspectiva que não encontre incompatibilidades profundas entre inflação e crescimento: "o inevitável aumento da pressão inflacionária poderá afetar a eficiência dos investimentos durante certo período, mas o efeito último sobre a taxa de crescimento será necessariamente reduzido" (PR, 1962, p. 33).

Possivelmente, é esse otimismo demasiado quando à capacidade de desenvolvimento autônomo da economia brasileira que confere certa estranheza a um segundo aspecto que perpassa todas as passagens importantes do texto. Se o binômio "mudança estrutural-investimento corretivo" é a pedra de toque que abre espaço e racionaliza o planejamento estatal, um outro par retorna insistentemente, como elemento ao mesmo tempo condicionante do sucesso e alheio à esfera de decisão do plano: a relação entre capacidade de importar e endividamento externo. Pois, apesar de todo o desenvolvimento industrial, da capacidade governamental de sustentação da "demanda agregada", do poder dinamizador da restrição externa; apesar de tudo isso, "a taxa de crescimento de 7\% [meta de crescimento anual médio para o triênio do plano] teria de ser reajustada para baixo se não fosse possível contar com adequado refinanciamento da dívida externa, como meio de manter a atual capacidade de importar" (idem, p. 46; colchetes nossos). Retrospectivamente, o eufemismo "revisão para baixo" e o pretérito perfeito do subjuntivo "fosse", sugerindo que o problema da dívida pudesse ser dado por resolvido, parece soar como um patético recurso retórico diante do insucesso do reescalonamento da dívida (de que o próprio Furtado dá relato; ver Furtado, 1989, pp. 161 s.) e do fraco desempenho do PIB em 1963. Porém, essa relativização da importância da capacidade para importar revela outra ambiguidade do plano, esta concernente à viabilidade de se levar a substituição de importações cada vez mais adiante: "caso seja necessário abandonar a hipótese de total refinanciamento da dívida, o processo de substituição poderá ser levado ainda mais longe, se bem não seja fácil manter a elevada taxa de crescimento que se está projetando" (PR, 1962, p. 54). O trecho final da frase dá mostras do elevado grau de hesitação que marca essa relação com o setor externo.

De todo modo, o que transparece no texto é que o otimismo quanto à capacidade de planejamento do Estado tem como correlato, no nível da estrutura econô- 
mica, um outro otimismo quanto à capacidade contínua de substituir importações independentemente do grau de profundidade da restrição externa. Não, portanto, um planejamento que elege o Estado como recusa a qualquer automatismo ou espontaneísmo das relações econômicas, mas um que se apoia no automatismo específico da substituição de importações - um automatismo que talvez cause mais problemas que soluções; que progride, mas só por meio de distorções; que precisa ser constantemente repensado, desfeito, reorientado; enfim, nosso patinho feio subdesenvolvido no mundo de belos cisnes do equilíbrio geral.

Por fim, gostaríamos de sumarizar alguns pontos básicos de nossa caracterização de planejamento no Plano Trienal, não com o intuito de exaurir seu sentido, mas de explicitar pontos de comparação com o PAEG:

1. Planejamento da economia pelo Estado encontra seu princípio de racionalização em um processo de desenvolvimento econômico que, por suas peculiaridades históricas, leva necessariamente a mudanças estruturais profundas e repentinas;

2. Cabe ao planejamento estatal prever essas mudanças estruturais de modo a evitar que elas se transformem em desequilíbrios e instabilidades cumulativos e permanentes;

3. Para tanto, o Estado deve realizar, incentivar e orientar adequadamente a formação de capital;

4. Nesse contexto, a restrição externa exerce um papel ambíguo: ora como constrangimento ao investimento, por reduzir a capacidade para importar matérias-primas, bens intermediários e bens de capital, ora como fator dinamizador, por aprofundar o processo de substituição de importações.

O leitor que se propuser uma leitura atenta do PAEG após o Trienal há de se deparar com, pelo menos, duas novidades e três ausências. De um lado, a noção de mercado, no sentido dinâmico de "sistema de preços", "forças de mercado", penetra insidiosamente no cerne da argumentação. Por outro, três expressões são silenciadas de modo quase escandaloso: estrutura, formação de capital e endividamento externo, que, se não desaparecem completamente, assumem um estatuto teórico e prático totalmente distinto. Por fim, a questão salarial ganha uma dimensão totalmente nova, assumindo prerrogativas de "política". Comecemos por esta última novidade.

Se o Trienal limita-se a colocar a questão dos salários, que devem "crescer com taxa pelo menos idêntica à do aumento da produtividade do conjunto da economia" (PR, 1962, p. 7), como um dos itens de seu objetivo de distribuição de renda, o PAEG prescreve uma política salarial muito mais clara, com a finalidade maior de "manter a participação dos assalariados no Produto Nacional”, visando "a preservar a capacidade de poupança nacional, a assegurar facilidades de emprego, e a permitir que os assalariados participem, sem defasagem, dos frutos do desenvolvimento econômico" (MPCE, 1964, p. 83). Note-se que ocorre uma certa inversão: o "pelo menos" a taxa de crescimento da produtividade, do Trienal, torna-se no PAEG um "no máximo"; se o plano de 1962 tinha por objetivo aumentar a parti- 
cipação dos assalariados no produto, o programa inicial do regime militar visava a barrar uma suposta ascensão recente, com base em argumentos estritamente econômicos, como o aumento da taxa de poupança e do nível de emprego, e parcialmente ideológicos, como limitar os reajustes às "regras naturais de mercado, mediante acordos espontâneos entre empregados e empregadores" (idem). Para atender a esses objetivos, o plano propõe sua famosa fórmula de reajuste (idem, p. 84). Resende identifica essa fórmula como uma contradição ou exceção ante a perspectiva "ortodoxa" ou liberal do plano: "na verdade, o programa desinflacionário do PAEG não é ortodoxo justamente nos pontos em que o contexto político permite a intervenção direta sobre as reivindicações incompatíveis" (Resende, 1982, p. 802). Se esta pode ser uma interpretação razoável das medidas práticas do governo no período, veremos que a reversão das expectativas liberais em prol de uma maior intervenção governamental é uma constante no texto, mas aqui sob uma estratégia bem diferente da do Trienal ${ }^{3}$.

Dentre as ausências de que falamos, o desaparecimento do endividamento externo como problema central é o mais fácil de se explicar e se deve ao fato do governo militar, gozando de maior "credibilidade" ou simpatia junto aos credores estrangeiros, ter tido o sucesso que o governo Goulart não teve quanto ao reescalonamento da dívida: celebrou-se a ata de Paris, uma série de acordos bilaterais que "representaram um desafogo cambial da ordem de US\$187,8 milhões, no biênio [1964-65], a que se acrescenta um alívio cambial de US\$ 56 milhões resultantes da extensão do mesmo esquema de Paris aos créditos de fornecedores privados americanos [...]" (MPCE, 1964, p. 125). Ou seja: o PAEG parte de uma condição externa muito mais favorável, que, ao contrário do contexto do Trienal, não se encontra em situação de iminente default e/ou colapso da capacidade de importar. Mas se o PAEG, diante da nova conjuntura, goza de relativa folga quando à imediaticidade do problema da dívida e das restrições às importações ${ }^{4}$, ele também encerra um modo bem mais direto de se relacionar com o setor externo: a capaci-

\footnotetext{
${ }^{3}$ A interpretação, sobre a questão salarial, de Mário Henrique Simonsen, participante ativo na elaboração do PAEG (ver Campos, 1994; p. 607; nota 263) e reputado autor da tal fórmula salarial, dá exemplo dessa diferença de estratégia: "é fora de dúvida que muitos reajustamentos salariais no Brasil têm sido institucionalmente forçados acima dos níveis que, normalmente, seriam pagos pelo mercado" (Simonsen, 1964, p. 39). Trata-se não mais de corrigir mudanças estruturais, mas fazer com que a economia convirja para um padrão de normalidade dado pelo sistema de mercado. Qual é, especificamente, esse padrão, que está “fora de dúvida”, é algo que não fica explícito nem no plano nem nos textos consultados...

${ }^{4}$ Por outro lado, no que concerte à situação interna, o contexto do PAEG é bem mais adverso: se 1962, ano da elaboração do Trienal, o PIB tem um crescimento de 6,6\% (IBGE), próximo à média histórica do pós-guerrra, com IGP (FGV) da ordem de 51,6\%, o PAEG é preparado num ano cujo crescimento é cerca de metade desse valor, $3,4 \%$ (sobre uma base já baixa devido ao crescimento de $0,6 \%$ em 1963), com inflação de $92,1 \%$ (IGP/FGV). Talvez esse recrudescimento da inflação, paralelo a um fraco desempenho do PIB, explique a superficialidade com que o PAEG trata os objetivos "rituais e clássicos" de crescimento, distribuição, emprego, e concentre-se de modo muito mais decisivo no "objetivo condicionante" da estabilização dos preços (ver Campos, 1994, p. 609-10).
} 
dade de importar é vista muito mais por seu aspecto limitador do investimento do que por seu efeito dinamizador sobre a substituição de importações. Esta é caracterizada não apenas como um processo em vias de atingir seus limites, mas também como uma das causas dos desequilíbrios condicionantes da estagnação econômica do início dos anos 1960. Sendo uma "reação defensiva, visando a superar circunstâncias adversas e dificuldades no balanço de pagamentos" (idem, p. 120), o processo de substituição de importações deu-se de modo desorganizado e contingente, inclusive limitando a produção industrial para exportação. Desse modo, a restrição externa é vista exclusivamente como limitação do investimento, relativizando-se seus possíveis efeitos desenvolvimentistas, considerados esgotados e indesejáveis. Mais ainda: o processo de substituição de importações, com seus desequilíbrios, deixa de ser $a$ forma específica de desenvolvimento dos países subdesenvolvidos, passando a constituir uma opção de desenvolvimento, que, exatamente pelos problemas que traz, teria sido de adoção incorreta no passado e inconveniente para o futuro. Os problemas deixam de ter uma origem estrutural e passam a ser tributários de falhas institucionais e das decisões (ou falta delas) dos agentes públicos.

A exposição do parágrafo anterior talvez tenha dado a impressão de que cometemos um certo engano: falamos em "silenciamento" da formação de capital no PAEG, mas a questão do setor externo não teve outro mote se não seu efeito sobre os investimentos. Não se trataria apenas de uma confusão terminológica? Uma análise mais detida da questão do "investimento" no PAEG sugere que não. A começar pela "Apresentação" que abre o Programa, assinada por Campos.

Nela, o economista sintetiza "dois modos bem distintos de encarar o processo de desenvolvimento econômico": um deles é ver "tudo em termos de intensificação do ritmo de formação física de capital", que ele desqualifica como "ilusão mecanicista"; outro, ao qual parece se filiar, propõe que o desenvolvimento seja "um processo através do qual os agentes econômicos, consumidores e empresas, adequadamente motivados, aprendem a mobilizar de forma eficiente os recursos materiais e humanos para realizar o potencial máximo de crescimento do produto real da comunidade" (idem, p. 5). Quer dizer: recusa-se um desenvolvimento econômico pautado pela mera expansão da formação de capital (que Campos talvez atribua injustamente ao Trienal ou ao "desenvolvimentismo" em sentido amplo), privilegiando-se uma perspectiva que preze pelo aumento da eficiência econômica possivelmente indutível pelo governo através de "motivações", estímulos adequados. A utilização de estímulos como instrumento fica mais clara na "Introdução" do Programa, cujo título é de um cinismo deslavado: "O sentido do planejamento numa economia democrática", onde o significado de "democrática" esgota-se no de "liberal" ou simplesmente "não socialista". Aí, ressalta-se que, em respeito à livre-empresa, o conteúdo do plano deve se restringir "à esfera de decisão dos poderes públicos", a qual inclui, entre outros aspectos, "os instrumentos da ação indireta do Governo sobre o setor privado, representados pela legislação econômica em geral e englobando as políticas tributária, creditícia, cambial etc.” (idem, p. 14). É verdade que o programa prevê um amplo quadro de investimentos públicos e de orientação dos investimentos privados, mas o que parece ser novo e decisivo aqui é a ênfase na 
constituição de instrumentos mediante os quais o governo possa atuar junto ao setor privado sem substituí-lo ou sobrepujá-lo na tomada direta de decisões.

É nesse contexto que “investimento" ganha uma nova dimensão semântica, não apenas como formação específica de capital, mas como uma variável quantitativa geral a ser utilizada como instrumento de indução do crescimento. Ao analisar os “determinantes da taxa de desenvolvimento", o texto identifica quatro variáveis que influenciam o produto real per capita: uma em sentido positivo, a taxa bruta de investimento, e três inversa ou negativamente, a relação incremental capital/produto, a proporção das depreciações no produto nacional e a taxa de incremento demográfico. Dentre elas, a taxa bruta de investimentos, definida como a participação do investimento agregado no PIB, é eleita "a de mais fácil manipulação pela política econômica" (idem, p. 21). O sentido específico de "investimento" nessa passagem fica mais claro quando, em seguida (pp. 21-22), os autores apresentam distintas projeções, que, dadas certas hipóteses sobre o comportamento das outras variáveis, relacionam uma determinada taxa de investimento com uma determinada taxa de crescimento do produto per capita. Desse modo, o conceito de investimento, em sua relação com o setor público, parece sofrer uma divisão: de um lado as inúmeras decisões específicas a respeito de onde, como e quanto investir, das quais o governo pode ou não tomar parte como objeto de política; de outro a taxa de investimento agregado, variável quantitativa geral que constitui instrumento privilegiado de intervenção governamental com vista a obter determinados fins de crescimento. Portanto, um dos objetivos do planejamento é criar o quadro institucional adequado ao controle dessa variável, quadro em que o investimento direto do governo e a orientação do investimento privado podem estar presentes, mas não como elementos isolados, sequer primordiais; o PAEG prevê todo um aparado de legislação tributária, reforma bancária e financeira, política creditícia e monetária, voltado para estimular a formação e circulação de poupança privada.

Nesse sentido, a situação do Trienal é radicalmente diferente, tanto em seu horizonte epistemológico como em suas condições políticas. Estas últimas ficam claras no capítulo dedicado às reformas administrativa do setor público, bancária, fiscal e agrária. Em míseras seis páginas, o trecho limita-se a apontar "diretrizes básicas que, admitidas, possam tornar as reformas previstas em efetivos instrumentos de política de desenvolvimento" (PR, 1962, p. 189). Essa aridez de exposição deve-se ao contexto democrático, pois o plano admite que se trata de "matéria, toda ela, a ser apreciada pelo Congresso Nacional” (idem). Sabemos que o PAEG não padecia dessa "rigidez institucional", de modo que suas "propostas" de reforma têm conteúdo muito mais preciso, a ser implementado por decreto, isso quando não resumem alterações legais já tomadas autoritariamente.

Quanto a suas bases epistemológicas, embora fale de "instrumentos de política econômica”, a concepção de investimento subjacente ao Trienal não apresenta nenhum vestígio de variável quantitativa instrumental geral que identificamos no PAEG. Lá, o valor agregado do investimento, que não é tematizado, parece estar diretamente subordinado às diversas condições específicas: conforme diluíam a previsibilidade das decisões econômicas, as mudanças estruturais prejudicavam a 
quantidade total de investimento apenas na medida em que constrangiam cada investimento particular. Ao Estado, portanto, cabia realizar ou estimular investimentos qualitativos para corrigir esses problemas estruturais, de modo a resgatar a confiança do investidor. Aqui, no PAEG, a atuação direta do governo sobre os investimentos integra-se a outros mecanismos, eventualmente mais importantes, para manter a taxa de investimento agregado em nível ideal ou desejável. Se essa taxa havia atingido patamares inferiores a tal nível, isso se devia a "desequilíbrios acumulados em anos anteriores", como "a ameaça de hiperinflação, os desníveis econômicos setoriais e regionais, a escassez de oportunidade de emprego para mão de obra e o desequilíbrio do setor externo", que, junto à "intranquilidade política e social", levava à "consequente frustração das expectativas e perda de eficiência do sistema produtivo" (idem, p. 20). Esses desequilíbrios, no diagnóstico do programa, não se subordinam a uma causa estrutural específica, mas, assim como o investimento e o problema externo, são tomadas como uma variável dada, sobre a qual é possível prescrever determinados meios específicos de intervenção.

O planejamento do PAEG, já podemos ver, tem um sentido bem distinto do subjacente ao Trienal. A mencionada "Introdução" pode nos servir novamente de referência. Ela deixa bem claro o escopo da atuação governamental - "estabelecimento das condições que assegurem a maior eficiência possível ao funcionamento da economia de livre-empresa, ou seja, o sistema de preços" - e do planejamento econômico - "definição sistemática e coerente, por parte do Governo, das medidas tendentes à criação da ordem dentro da qual operará aquilo que se convencionou chamar de 'forças de mercado' [...]" (idem, p. 13). Neste caso, numa estratégia paralela à do Trienal, a apresentação liberal sofre uma guinada para atender às especificidades dos países subdesenvolvidos. O conteúdo da reversão, no entanto, tem natureza radicalmente distinta. No Plano Trienal, é a especificidade histórico-estrutural do subdesenvolvimento econômico que cria condições adversas sob as quais o planejamento estatal deve agir produzindo modificações estruturais corretivas. Vejamos ipsis litteris os "princípios pouco controvertidos" que o PAEG identifica como específicos dos países economicamente subdesenvolvidos:livre jogo das forças de mercado não garante necessariamente a formação de um volume desejável de poupança;

a) sistema de preços nem sempre incentiva adequadamente a formação de economias externas (investimentos em educação, estradas etc.), dada a desvinculação entre a respectiva rentabilidade e a produtividade social correspondente;

b) livre jogo das forças de mercado não leva necessariamente a uma distribuição satisfatória da renda nacional entre pessoas e regiões;

c) a eficiência do sistema de preços pode ser apreciavelmente distorcida pelas imperfeições espontâneas ou institucionais do mercado (MPCE, 1964, p. 13).

Note-se como a questão da falha estrutural é substituída por falhas de diversas naturezas - contingentes, factuais, institucionais - que levam à ineficiência dos mecanismos que, teoricamente, manteriam uma situação de equilíbrio de mercado 
e distribuição de renda desejável. Planejar, aqui, enquanto "criação da ordem dentro da qual atuem as forças de mercado", significa desenvolver aperfeiçoamentos institucionais que tragam maior eficiência à suposta função reguladora do sistema de preços $^{5}$.

Dito isso, poderíamos sumarizar a análise do PAEG em quatro contrapontos aos itens da síntese do Trienal:

1. Planejamento governamental encontra seu espaço nas falhas do sistema de mercado que se desenvolveram historicamente nos países subdesenvolvidos; seu objetivo é alterar e desenvolver não os parâmetros estruturais da economia, mas os parâmetros institucionais sobre os quais se fundamenta o funcionamento do sistema de preços;

2. As variáveis de controle e os desequilíbrios econômicos devem ser tomados como dados sobre os quais cabe ao governo desenvolver instrumentos específicos de intervenção, preferencialmente indiretos;

3. Investimento é apenas uma dessas variáveis de controle; a função central do governo em relação a ele não é apenas a de decidir e orientar, mas também, e primordialmente, a de estimular um nível de investimento agregado desejável;

4. A restrição externa é apenas uma limitação à obtenção desse nível desejado de investimento face ao esgotamento (e à inconveniência) do processo de substituição de importações.

\section{CONCLUSÃO}

Retomando uma de nossas interrogações iniciais para responder se a continuidade das práticas de política entre o período do Trienal e o do PAEG corresponde à continuidade da formulação textual dos planos, de seus diagnósticos e de seus horizontes teóricos, a resposta seria certamente não. Como vimos, a afirmação: "entre o Plano Trienal e o PAEG, a principal diferença está na distinta configuração de forças políticas existentes em seus momentos” (Resende, 1982, p. 802) só é válida quanto às variáveis de política efetivamente verificadas no período. No que concerne a suas bases epistemológicas, a suas perspectivas históricas, à situação econômica pressuposta e às projeções para o futuro, os dois programas são radicalmente distintos. Tentamos mostrar, ainda, que o problema do investimento nos permite compreender o que há de fundamental nessa diferença: enquanto o Trienal elege como papel do Estado a seleção qualitativa de investimentos corretivos, o

\footnotetext{
${ }^{5}$ Novamente, é a "franqueza" da pena de Mário Henrique Simonsen que demonstra o grau de cinismo ou ingenuidade tecnicista característico da perspectiva dos autores. Sua defesa da fórmula salarial é de uma insensibilidade sócio-histórica sem par: "uma fórmula desse tipo tem a vantagem de substituir um infindável jogo de greves e pressões por um simples cálculo aritmético” (Campos \& Simonsen, 1975, p. 112).
} 
PAEG foca em aprimoramentos institucionais que permitam ao Estado manter e incentivar um nível quantitativo de investimento agregado. Essas perspectivas não são simplesmente distintas, mas marcam uma divergência importante quanto à natureza e os limites da atuação estatal na economia. Não que, até 1964, a atuação histórica do Estado brasileiro tenha sido marcada simplesmente com intervenções ostensivas, sem preocupação com mecanismos macroeconômicos instrumentais. Nem que, a partir do PAEG, esses mecanismos tenham surgido do nada e se imposto como forma predominante. O que tentamos indicar a partir da análise dos textos é que há uma inversão teórica na hierarquia entre intervenção estatal direta e indireta, inversão esta que produz efeitos concretos na organização institucional e nas práticas de política econômica posteriores. Não seria este um bom ponto de partida para pensarmos por que muitas das reformas de base foram retomadas no contexto do PAEG com "sentido" diferente?

O historiador de espírito mais pragmático há de objetar que tais conclusões não justificam o demorado da análise, no máximo instigam curiosidade. O PAEG, ao menos, se não teve grande sucesso como plano de estabilização, logrou implementar grande parte de suas reformas institucionais, de modo que perscrutar os pressupostos que motivaram seus autores talvez encerre alguma valia histórica. Mas o Trienal?! Esse não chegou sequer próximo da realização, inviabilizado pela instabilidade política, social e institucional que marcou a presidência de Goulart... Não se trataria de documento de pouca significação prática, escrito às pressas, com finalidade meramente conjuntural? Um projeto que, como reconheceu seu próprio coordenador, submete-se menos às necessidades econômicas do que a causas políticas urgentes e pouco conciliáveis (ver Furtado, 1989, pp. 156-163)?

Ora, pois é exatamente essa imbricação na política conjuntural que torna reveladora a elaboração econômica do Trienal. O que nos parece profundamente interessante, neste caso é interrogar por que seus elaboradores fizeram apelo a determinada narrativa histórica e a certos critérios de diagnóstico e intervenção como forma de legitimar socialmente suas ações, de "aliciar apoio nas diversas classes”. Mais ainda, interessa interrogar por que essas narrativas e esses critérios não obtiveram sucesso nem do ponto de vista técnico, como medidas de estabilização e crescimento, nem do ponto de vista político, como estratégia de legitimação. Afinal, a partir dessas questões podemos refletir sobre dois modos distintos de compreender as crises socioeconômicas. Se, por um lado, pensarmos a instabilidade política do período de um ponto de vista exclusivamente objetivo, seja como inconciliabilidade dos interesses dos grupos sociais hegemônicos, seja como fragilidade sistêmica da economia brasileira, então o Trienal realmente se resume a uma elaboração abstrata com pouco efeito. Mas será que essa perspectiva não despreza algo de fundamental, qual seja, a relação entre nossos processos cognitivos e nossas práticas sociais? Pois poderíamos, por outro lado, pensar tal instabilidade como crise dos critérios que legitimaram o conhecimento e as práticas estatais de intervenção sobre a sociedade brasileira no pós-Guerra, critérios estes que encontrariam sua expressão econômica mais bem acabada no nacional-desenvolvimentismo. Nesse sentido, o "fracasso" do Trienal - suas intermináveis ambiguidades, sua inapli- 
cabilidade técnica, sua incapacidade de aglutinar uma base social ampla e efetiva - deixa de ter um sentido direto: não mais simples consequência de um impasse dado e externo, mas expressão totalmente integrada à lógica que produziu esse impasse, do qual os conflitos sociais e o sistema econômico tomam parte, mas de modo dificilmente isolável.

Considerar, por sua vez, a instabilidade política como decorrente também de impasses de ordem cultural e cognitiva, embora potencialmente problematize a tese de que 1964 tenha sido a suspensão súbita de um certo desenvolvimento harmônico anterior, nada tem de condescendente com qualquer justificativa do Golpe enquanto necessidade histórica. Isso porque o PAEG não pode ser minimamente caracterizado como uma solução de compromisso. Sua assertividade e segurança aparentemente maiores não se devem à reconquista de um consenso social amplo, por menor que fosse, mas à consciência de que, ao menos no curto ou médio prazo, tal consenso deixou de ser necessário à elaboração das políticas públicas, graças a expedientes de força. Essa diferença fica claramente marcada no modo como cada texto situa suas inconsistências: se, no Trienal, estas aparecem no contexto de interpretações ricas e profusas, típicas de quem reconhece dever explicações a uma instância crítica ou autocrítica, o PAEG pode valer-se da confortável estratégia de restringir seus pontos problemáticos ao âmbito dos pressupostos "fora de dúvida" ou "pouco controvertidos". Portanto, não parece plausível sequer considerar este último como o resultado técnico e coerente de um recurso pontual ao autoritarismo como meio de solucionar a crise socioeconômica. Trata-se, pelo contrário, da interrupção do processo histórico de busca dessa solução, suspenso em nome de uma certa "ingenuidade" autocrática e tecnicista. Esta não consiste simplesmente em retórica superficial, mas assume um papel necessário de legitimação diante da impossibilidade de recorrer honestamente a bases sociais como fundamento da ação econômica do governo. Tal impossibilidade, com seu tecnicismo correlato, não será das características menos determinantes do desenvolvimento ulterior do Estado brasileiro.

\section{REFERÊNCIAS BIBLIOGRÁFICAS}

BERCOVICI, G. (2010). “'O direito constitucional passa, o direito administrativo permanece’: a persistência da estrutura administrativa de 1967”. In: SAFATLE \& TELES. (2010; org).). O Que Resta da Ditadura. São Paulo: Boitempo. p. 77-90

CAMPOS, R. O. (1994). A Lanterna na Popa. Memórias. Rio de Janeiro: Topbooks.

CAMPOS, R. O. \& SIMONSEN, M. H. (1976). A Nova Economia Brasileira. Rio de Janeiro: José Olympio.

FISHLOW, A. (1974). “Algumas reflexões sobre a política econômica brasileira após 1964”. Estudos Cebrap. Vol. 7. Janeiro-março de 1974. p. 6-65.

FOUCAULT, M. (2007). Security, Territory, Population. Lectures at the College de France, 1978. Nova Iorque: Palgrave Macmillan.

FOUCAULT, M. (2008). The Birth of Biopolitics. Lectures at the College de France, 1978-9. Nova Iorque: Palgrave Macmillan.

FURTADO, C. (1985). A Fantasia Organizada. Rio de Janeiro: Paz e Terra. 
FURTADO, C. (1989). A Fantasia Desfeita. Rio de Janeiro: Paz e Terra.

FURTADO, C. (2007). Formação Econômica do Brasil. 34.ed. São Paulo: Companhia das Letras.

HERMANN, J. (2002). "Financial structure and financing models: The Brazilian experience over the 1964-1997 period". Journal of Latin American Studies. Vol. 34(1). p. 71-114

IANNI, O. (2009). Estado e Planejamento Econômico no Brasil. Rio de Janeiro: Editora UFRJ.

MACARINI, J. P. (2005). “A política econômica do governo Médici: 1970-1973”. Nova Economica. Vol. 15(3). Setembro-dezembro de 2005. p. 53-92

OLIVEIRA, F. A. (1981). A Reforma Tributária de 1966 e a Acumulação de Capital no Brasil. São Paulo: Brasil Debates.

RESENDE, A. L. (1982). “A política brasileira de estabilização: 1963/68”. Pesquisa e Planejamento Econômico. Vol. 12(3). Dezembro de 1982. Rio de Janeiro. p. 757-806

SIMONSEN, M. H. (1964). A Experiência Inflacionária no Brasil. Instituto de Pesquisas e Estudos Sociais (IPES). Rio de Janeiro.

SOCHACZEWSKI, A. C. (1983). Desenvolvimento Econômico e Financeiro do Brasil: 1952-1968. São Paulo: Trajetória Cultural.

VIEIRA, B. M. (2010). “As ciladas do trauma: considerações sobre história e poesia nos anos 1970". In: SAFATLE \& TELES (2010; orgs). O Que Resta da Ditadura. São Paulo: Boitempo. p. 151-176

WALLERSTEIN, M. (1980). "The collapse of democracy in Brazil: Its economic determinants". Latin American Research Review. Vol. 15(3). p. 3-40

ZINI Jr., A. A. (1982). "Uma avaliação do setor financeiro no Brasil: da reforma de 1964/5 à crise dos anos oitenta”. Dissertação de mestrado. Unicamp. 